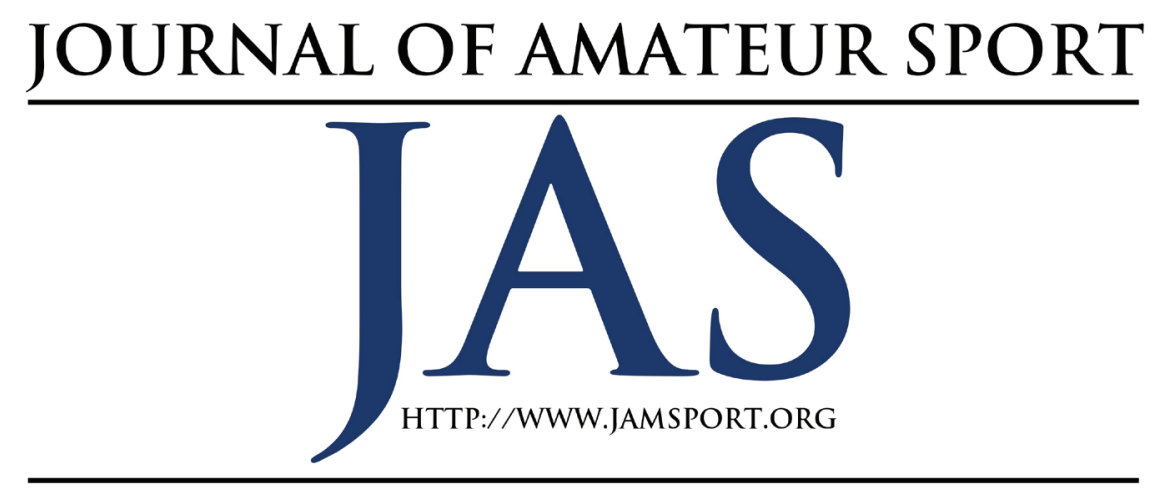

\title{
The End is Not the Injury: Posttraumatic Growth After Sport Injuries
}

\author{
Sasa E. Vann \\ Kelse Freiburger
}

\author{
Matthew Moore \\ Hannah Johnson
}

Ball State University

\begin{abstract}
This quantitative study explored whether serious injuries in varsity high school or collegiate athletes could produce Posttraumatic Growth (PTG). The impact of injury (season- or career-ending) and an athlete's highest level of competition played (varsity high school or collegiate) were examined on five elements on the 21-item Posttraumatic Growth Inventory (PTGI): (1) relating to others, (2) new possibilities, (3) personal strength, (4) spiritual change, and (5) appreciation of life. This study provides evidence that sport level does not impact an athlete's ability to produce PTG and bring awareness to trauma and the role PTG can have in an athlete's life.
\end{abstract}

Keywords: posttraumatic growth, sport, athletic injury, high school, college

$\mathrm{n}$ athlete's purpose is often
related to the goal of their team
and the pursuit to excel within the parameters of their sport. The level at which an athlete identifies with those goals and their role as it relates to sport is a characteristic of their athletic identity (Cabrita, Rosado, Leite, Serpa, \& Sousa, 2014). Injury or another isolated incident can be a factor that alters an athlete's identity (Heird \& Steinfedt, 2013). Of particular concern are athletes who do not plan on retiring from their sport; rather, they are forced for reasons outside of their control (e.g., injury or illness) to find new meanings in life.

Athletes who are forced into retirement from injury may attempt to hold onto their athletic identity as a means of coping or as a way to maintain a sense 
of normalcy in their life (Cosh, Crabb, \& LeCouteur, 2013; Stambulova, Stephan, \& Japhag, 2007). It is important for those working within athletics to understand in addition to their physical impairment they may suffer in less visible ways (i.e., stress and emotional isolation). In particular, those working with athletes need to identify what causes some athletes to respond positively versus negatively in their behavioral and social lives following serious injury (Clement, Arvinen-Barrow, \& Fetty, 2015; Cosh, Crabb, \& LeCouteur, 2013). In other words, what does it take to ensure an injury does not cause negative life implications on an athlete's purpose during their transition through injury?

A report conducted by the U.S Department of Health and Human Services (HHS) analyzed injury rates from 20112014 on persons age five years and older. Injury was defined as the cause of an external, traumatic, and nonfatal event needing medical attention. During this four-year period, approximately 8.6 million sports and recreation-related injuries occurred (Sheu, Chen, \& Hedegaard, 2016). An estimated $65 \%$ of those injuries occurred during an athlete's peak years of athletic involvement (16-25 years). Half of the 8.6 million injuries required treatment by a doctor and had an impact on sports performance (Sheu et al., 2016). Given the extraordinary rates at which athletes experience injury nationwide, it is clear there is an urgency behind research focusing on the impact these injuries can have on an athlete's psychosocial well-being (Kampman, Hefferon, Wilson, \& Beale, 2015).

This study focused on the percentage of athletes between the ages of 16-25 years who experienced injuries. Of these athletes, over 30\% sustained a concussion in response to their athletic participation (Ferguson, Green, \& Hansen, 2013). Furthermore, a vast majority of athletes in this age range experienced some form of athletic injury that required treatment by training and medical staff. While injuries can range from minor to severe, research indicates that injuries sustained by an athlete can cause psychosocial and behavioral health risks such as depression, anxiety, and suicidal ideation (Koren, Norman, Ayala, Berman, \& Klein, 2005; Sheinbein, 2016).

While research on injury-response is available, this study built upon existing literature by exploring the impact an athletic injury has on an athlete's development of Posttraumatic Growth (PTG). Rather than exploring the negative behavioral health and psychosocial implications of an injury, this study explored a strengthbased perspective in an attempt to learn more about helping athletes grow from their traumatic experience. No study to date explores the development of PTG in athletes after experiencing an injury.

The term PTG was coined in 1993. Posttraumatic Growth occurs when humans overcome adversity and thrive in the face of trauma. This study considered a season - or career-ending injury 
as a form of adversity and trauma to an athlete. Within PTG research, there are five domains used to determine the level of growth experienced by individuals: (1) personal strength, (2) appreciation for life, (3) new possibilities, (4) spiritual change, and (5) relating to others (Tedeschi \& Calhoun, 1996). For an athlete with an injury, PTG is an experience in which the negative trauma could provide them with an opportunity to see new possibilities and turn to others for support related to their injury (Ramos \& Leal, 2013). Given the previous research which suggests PTG can positively impact feelings relating to others after trauma (Tedeschi \& Calhoun, 1996; Zoellner \& Maerker, 2006) there remains the possibility that PTG could help soften the loss of athlete identity, provide an athlete with a greater sense of belonging, and reduce stress symptoms. The researchers anticipated in developing PTG, athletes would see the end is not the injury; rather, the injury is an opportunity to redefine their lives.

Research of this nature should provide information to athletic trainers and behavioral health professionals on helping athletes (1) build strong support pre- and post-injury, (2) recognize new possibilities post-injury, and (3) maintain an appreciation of life despite athletic implications. Positively impacting the lives of athletes, in addition to educating professionals, could significantly impact how future generations respond to injuries that threaten an individual's psychosocial well-being.

\section{Literature Review}

\section{Athletic Injury}

A reportable injury was defined as an injury that: (1) occurred as a result of participation in an organized athletic practice or competition, (2) required the attention of an athletic trainer or physician, and (3) resulted in the restriction of an athlete's participation in their sport (Kerr, Hayden, Dompier, \& Cohen, 2015). Of the 30 million children and adolescents that play organized sports, it is estimated that nearly 2 million will sustain a reportable injury in a given year (Centers for Disease Control and Prevention, CDC, 2015). At the collegiate level, approximately 4,000 athletes each year experience a season- or career-ending injury (Kay, Register-Mihalik, Gray, Djoko, Dompier, \& Kerr, 2017). This rate of serious injury is comparable to what athletic trainers report in high school sports (Kerr et al., 2015). This is important to note because athletes who sustain an injury, such as a concussion, are more likely to sustain another (Kutcher \& Ecker, 2010). Therefore, the group of athletes reporting injuries in high school may soon overlap with those season- or career-ending injuries at the collegiate level. For this reason, it is even more important to understand the coping strategies of these athletes as they may be at greater risk then even they realize.

Within these season- or career-ending athletic injuries there are a variety of types, causes, and implications. Two classes of injury, chronic and acute, are typically treated very differently and can 
affect the athlete in different ways (Prentice, 2014). An acute injury is an injury that happens in one instance and is typically much more traumatic. Acute injuries include the loss of bodily function or structure, immediate sensation of pain and discomfort, and incapacitate an athlete (e.g., a torn knee ligament). A chronic injury is an injury that happens over time with repeated stress to the body (e.g., overuse injuries). A common example of a chronic injury is any tendonitis in the body, usually treated by discontinued use of that body part (e.g., the knees or ankles of long distance runners).

\section{Injury Response}

Athletes respond to injuries in a variety of ways. Of particular concern is the number of athletes who respond to an injury in ways detrimental to their behavioral health and psychosocial well-being (Ivarsson, Tranaeus, Johnson, \& Stenling, 2017). Amongst elite athletes, research indicates the adversity faced from their injuries can cause them to feel a sense of loss related to their sport, which in turn motivates them to grow. It is unknown whether this same pattern is observed at the high school or collegiate level (Tamminen, Holt, \& Neely, 2012). Current research does, however, link injury response to feelings of stress or anxiety, challenges with anger management, depression, problems with motivation, loss of identity, and alcohol and substance misuse (Clement et al., 2015; Cosh et al., 2013). In order to understand the athlete more completely, it is important to com- prehend why there remains a difference in injury response type.

The identity loss, anxiety, and other responses an athlete feels in conjunction with their injury may result in the development of Posttraumatic Stress Disorder (PTSD) (Newcomer \& Perna, 2003; Malhotra \& Chebiyan, 2016). The behavioral expressions related to PTSD include: (1) aggressive outbursts, (2) avoidance of others (e.g., teammates and coaches), (3) avoidance of any athletic endeavor, (4) recurrent recollections of the injury, and (5) a sense of an unknown future. Due to the injury, an athlete may experience recollections in the form of dreams or nightmares related to their injury and perceived insufficiency of ability. Troubles with sleep can indirectly increase risk for aggressive outburst or re-injury; while aggression is often seen as a positive element in the sport community the negative outcomes (e.g., red flags, ego orientated game play, negative self-talk, and increased risk of injury, etc.) outweigh the possibility of improved ability through increased aggression. There are also concerns about the degree to which athletes view their injury as a personal failure (Heinrich, Spencer, Fehl, \& Poston, 2012).

Blame, shame, and guilt are common mechanisms adopted after an injury or trauma. These feelings can be isolating (e.g., the athlete thinks they are the only person who felt that way and does not share the emotions of which they are ashamed). When athletes use self-blame in relation to their injuries, they are more 
likely to overuse their body, increasing their chance of re-injury (Timpka et al., 2015). Re-injury continues to damage the physical as well as the mental well-being of the athlete. Athletes may respond to injury with negative coping strategies, thus, implementing best practices for helping athletes work through identity challenges is an important skill for health professionals to develop (Martin, Fogarty, \& Albion, 2014). This is a gap that should be addressed, especially given the vast amount of athletic injuries within a given year (Williams \& Krane, 2015). In particular, there is a need for recommendations for how professionals can help athletes process their injuries, find new purpose in life, enhance their self-confidence, improve their social support, and practice strategies for appropriately coping with the trauma they experienced.

A possible moderator of negative affects post-injury may be support, specifically the perception of support compared to quantifying how much was received (DeFreese \& Smith, 2011). Without knowing exactly what works best for each individual athlete, researchers have started to use PTG to measure post-injury psychosocial growth (Salim, Wadey, \& Diss, 2016; Zoellner \& Maerker, 2006). The following section will provide further insight into how PTG may occur.

\section{Posttraumatic Growth}

A concept that practitioners could use to support athlete growth after an injury is PTG (Salim, Wadey, \& Diss, 2016). The process of growth does not necessarily mean the pain associated with injury is gone and it does not mean that growth was actually sought. Growth is something that a person comes to acknowledge internally, not something they consciously seek (Salim, Wadey, \& Diss, 2016). Posttraumatic growth is the idea that humans can have a positive experience that occurs after a traumatic event (Tedeschi \& Calhoun, 1996) and there is a beneficial change seen (Zoellner, \& Maerker, 2006).

While the use of PTG concepts to help athletes overcome injury appears non-existent in academic literature, PTG is associated with helping individuals overcome a variety of traumatic events. First, individuals who experienced natural disasters were able to find personal strength, an appreciation for life, and the development of new social supports through their experiences (Nishi et al., 2016; Nolen-Hoeksema \& Davis, 2004). Nishi and colleagues (2016) identified the domain of appreciation for life was higher among Japanese natural disaster health care professionals who had higher levels of resilience prior to their natural disaster experience. Second, patients who battled cancer also showed evidence of PTG. These patients often found renewed spiritual change, personal strength, and new possibilities for their life (Dabhauer et al., 2013; Morrill et al., 2008; Sears \& Stanton, 2003). For example, among cancer patients with higher PTG scores, they reported they were able to better manage their challenges with cancer (Dabhauer et al., 2013). 
Third, Engelhard and colleagues (2015) investigated soldiers deployed to Iraq and their perception of growth. Time (5 months, 15 months, and return home) was correlated with the level and type of PTG domain the soldiers experienced. For example, the soldiers responded that the domain of new possibilities was highest in terms of areas of growth at the 15-month mark and after the soldiers returned home. Still, the soldiers who reported high growth overall earlier in their deployment had higher levels of posttraumatic stress after returning home. The authors suggest this may be due to perception of growth abilities versus their actual growth (Engelhard et al., 2015)

Fourth, Duan, Gao, and Gan (2015) found individuals who experienced physical abuse and sexual abuse found personal strength and the development of new supports as a result of their experiences. Growth and the perception of growth was possible in these experiences, which implores the question. Can athletes have perceptions of PTG after athletic injuries too?

\section{Current Study}

The study provides insight to possible strategies for helping varsity high school and college athletes experience personal growth from their injuries. This information could be valuable for inter-professional teams who work to promote the health and well-being of athletes (e.g., athletic trainers, sport psychologists, social workers, and other physical and be- havioral health providers). Additionally, helping athletes grow from their current traumas could provide a buffer for future traumas in which they might experience in their athletic, academic, social, and professional lives (Zoellner \& Maerker, 2006).

\section{Methods}

The overall goal of this research was to explore whether season- or career-ending injuries in college-athletes can produce PTG. This study explored the impact of season- or career-ending injuries and an athlete's highest level of competition played (varsity high school or collegiate) on five domains of PTG: (1) relating to others, (2) new possibilities, (3) personal strength, (4) spiritual change, and (5) appreciation of life (Tedeschi \& Calhoun, 1996).

\section{Research Design}

For this exploratory study, the researchers used a cross-sectional, webbased survey design to collect information from former varsity high school athletes and current or former collegiate athletes. To determine the desired sample size, the researchers began by selecting the statistical test necessary to answer the research questions. The researchers used a two-way Analysis of Variance (two-way ANOVA) for answering the research question. The researchers used a statistical power of 0.80 and a medium effect size 0.25 . The researchers used confidence intervals of 0.05 . Considering 
these factors, the desired sample size for this study was a minimum of 83 athletes (Faul, Erdfelder, Buchner, \& Lang, 2007). The final sample included 93 athletes.

In order to obtain the desired number of responses from athletes, the researchers used an availability sampling approach and sent an email request for participation to all students, staff, and faculty at a Midwestern Division I university. To be eligible for participation, participants must have experienced a season- or career-ending injury as a result of their athletic participation. Participants must also have had competition experience at either the varsity high school or collegiate level. All other individuals were excluded from this research study. The original email contained a copy of the informed consent and a link to the webbased survey. Researchers sent out two reminder emails to bolster the response rate. Reminder emails were sent two and four weeks after the initial recruitment email.

\section{Study Participants}

The researchers collected information about the age, gender, race, level of athletic competition during the injury (varsity high school or collegiate), sports played, role on an athletic team (starter or non-starter), severity of the athletic injury (season- or career-ending), and type of injury (see Table 1). The sports played at the highest frequency included: track and field $(n=21)$, football $(n=15)$, and soccer $(n=11)$. Athletes in this sample participated in 18 different sports.
Just over half $(n=48)$ of the participants reported they were multi-sport athletes. The athlete's injuries ranged from 1-50 years post injury at the time of the survey completion. The mean years post injury was 7.6 years and the mode was 2.5 years $(n=20)$. Athletes experienced a variety of season- and career-ending injuries. Common injury types included: torn knee ligaments, concussions, spinal cord injuries, broken bones, and overuse injuries.

\section{Measures/Instruments}

Due to high reliability and validity scores, the researchers used the Posttraumatic Growth Inventory (PGTI) (Tedeschi \& Calhoun, 1996) for the web-based survey. The Posttraumatic Growth Inventory is an instrument that measures growth after adversity in five areas: (1) relating to others, (2) new possibilities, (3) personal strength, (4) spiritual change, (5) appreciation of life. The Inventory has a high internal consistency $(\alpha=0.94)$ and test-retest reliability $(\alpha=0.85)$ (Tedeschi \& Calhoun, 1996). Confirmatory factor analyses indicate an acceptable model of fit (CFI > 0.95) (Tedeschi \& Calhoun, 1996).

The Posttraumatic Growth Inventory consists of 21 questions (Tedeschi \& Calhoun, 1996). For the purposes of this study, questions were explored on the degree to which change occurred in the athlete's life as a result of their injury. Participants answered all 21 questions using a six-point scale with endpoints $(0$ $=\mathrm{I}$ did not experience this change as a 
Table 1

Athlete Demographics (N = 93)

\begin{tabular}{|c|c|c|}
\hline $\begin{array}{l}\text { Demographic } \\
\text { Characteristic }\end{array}$ & $N$ & $\%$ \\
\hline Age (M, SD) & $25.10(10.62)$ & \\
\hline \multicolumn{3}{|l|}{ Gender } \\
\hline Male & 42 & $45 \%$ \\
\hline Female & 51 & $55 \%$ \\
\hline \multicolumn{3}{|l|}{ Race } \\
\hline White & 75 & $81 \%$ \\
\hline Black & 11 & $12 \%$ \\
\hline Multi-racial & 5 & $5 \%$ \\
\hline Asian & 1 & $1 \%$ \\
\hline Pacific Islander & 1 & $1 \%$ \\
\hline \multicolumn{3}{|l|}{ Competition Level } \\
\hline Varsity High School & 49 & $53 \%$ \\
\hline Collegiate & 44 & $47 \%$ \\
\hline \multicolumn{3}{|l|}{ Role on Athletic Team } \\
\hline Starter & 86 & $93 \%$ \\
\hline Non-starter & 7 & $7 \%$ \\
\hline \multicolumn{3}{|l|}{ Severity of the Injury } \\
\hline Season-ending & 50 & $54 \%$ \\
\hline Career-ending & 43 & $46 \%$ \\
\hline
\end{tabular}

result of my injury) to ( $5=\mathrm{I}$ experienced this change to a very great degree as a result of my injury). The five areas of PTG measured by this scale had a minimum of two questions (spiritual change) to seven questions (relating to others). In addition to answering questions from the Posttraumatic Growth Inventory, partic- ipants answered a series of demographic and sport-related questions. The total survey took approximately 10-15 minutes to complete in the Qualtrics ${ }^{\mathrm{TM}}$ system.

\section{Data Analysis}

There were two independent variables in this study - injury severity (season- or 
career-ending) and highest level of athletic competition (varsity high school or collegiate). These variables were categorical. The dependent variable for this study was the overall Posttraumatic Growth Inventory score. This score was the sum of scores for all 21-inventory questions. The greater the PTG score the more growth occurred for that individual (Tedeschi \& Calhoun, 1996).

The researchers used descriptive statistics to provide details about the sample and an overview of the inventory results. The researchers used a two-way ANOVA to explore the impact injury severity and competition level had on an athlete's PTG. This test allowed the researcher to examine the mean differences between levels of the independent variables on the dependent variables. The use of a twoway ANOVA not only protected the inflation of type I error, but also allowed the researcher to examine group differences on the dependent variable (Field, 2009).

\section{Results}

\section{Descriptive Statistics}

Overall, athletes experienced signs of PTG at a moderate degree as a result of their injury $(M=3.13, \mathrm{SD}=.99)$ (See Table 2). Athletes were most likely to experience signs of personal strength as a result of their injury $(M=3.88, \mathrm{SD}=$ 1.16). This was followed by the discovery of new possibilities $(M=3.35, \mathrm{SD}=$ $1.28)$ and a new appreciation for life ( $M$ $=3.34, \mathrm{SD}=1.18)$. Athletes were least likely to find spiritual change as a result of their injury $(M=2.16, \mathrm{SD}=1.42)$ and to relate to others through their injuries $(M=2.76, \mathrm{SD}=1.19)$.

\section{Statistical Assumptions}

The researchers used a two-way ANOVA to explore the impact of competition level and injury severity on levels of PTG perception. Before using this test, the researchers tested for assumptions. All assumptions for a two-way ANOVA were met.

Table 2

Results from the Posttraumatic Growth Inventory

\begin{tabular}{lll}
\hline PTG Factor & $\begin{array}{l}\text { Factor Total } \\
M(S D)\end{array}$ & $\begin{array}{l}\text { Factor Average } \\
M(S D)\end{array}$ \\
\hline Relating to Others & $19.29(8.31)$ & $2.76(1.19)$ \\
New Possibilities & $16.77(6.40)$ & $3.35(1.28)$ \\
Personal Strength & $15.51(4.64)$ & $3.88(1.16)$ \\
Spiritual Change & $4.29(2.85)$ & $2.16(1.42)$ \\
Appreciation of Life & $10.02(3.55)$ & $3.34(1.18)$ \\
Overall Score & $65.88(20.77)$ & $3.13(0.99)$ \\
\hline
\end{tabular}




\section{Results of the Two-way ANOVA}

Main effect - competition level.

The results of the two-way ANOVA showed no overall significant difference between the highest level of competition played by athletes and their PTG scores $\left(F_{(3,89)}=0.13 p>0.05\right)$. In other words, whether an athlete was injured during varsity high school $(M=65.14)$ or collegiate athletics $(M=66.73)$ did not influence their PTG scores. Competition level accounted for less than $1 \%$ of the variance in PTG scores.

\section{Main effect - severity of the inju-} ry. The results of the two-way ANOVA showed no overall significant difference between season- and career-ending injuries and PTG scores $\left(F_{(3,89)}=0.08 p>\right.$ $0.05)$. In other words, whether an athlete experienced a season- $(M=66.56)$ or career-ending $(M=65.30)$ injury did not influence their PTG scores. The severity of an athlete's injury accounted for less than $1 \%$ of the variance in PTG scores.

\section{Interaction effect - competition} level by the severity of the injury. The results of the two-way ANOVA showed no significant competition level by the severity of injury interaction effect on PTG scores $\left(F_{(3,89)}=0.685, p>0.05\right)$. In this study, the interaction between the independent variables accounted for less than $1 \%$ percent of the variance in overall PTG scores.

\section{Discussion}

The purpose of this study was to examine whether or not PTG were possible in athletes playing at both the collegiate and varsity high school level with a history of season- or career-ending injury. Given the trauma-related nature of PTG to other events (e.g., natural disasters, head injuries, and cancer), the athletic community should have knowledge on how a sport injury could impact an athlete in a similar way.

\section{Research Findings}

Overall PTG. Compared to research investigating PTG retrospectively with the PTGI amongst people who survived serious motor vehicle accidents ( $M$ $=41.2$ ) (Nishi, Matsuoka, Yonemoto, Noguchi, \& Kim, 2010) the growth observed within the athletic population was 25 points higher $(M=66)$ on the PTGI. Our athlete population also scored higher in PTG when compared to a population of coronary artery disease outpatients $(M=47.3)$ (Leung, Alter, Prior, Stewart, Irvine, \& Grace, 2012).

Still, the growth perceived by these athletes fails to support how or why PTG occurs within this population. When all five types of growth were compared the growth areas of spiritual change and relating to others were the least likely to occur. The lack of change in spirituality does not mean athletes are not faithbased individuals; rather, the occurrence of their injury did not cause them to find greater solace in spirituality. The limited occurrence of growth amongst the student-athletes in relating to others may be due to the feelings of isolation related to sustaining an injury (Heird \& Steinfedt, 2013). This change in an athlete's social 
environment may have made it more difficult to perceive similarities with others.

It is important for those working with athletes to understand where athletes are developing the most growth, but also the areas that are less likely to produce growth for athletes. Post-injury interventions can first focus more specifically on the types of growth that may be most likely to occur (personal strength, discovery of new possibilities, and a new appreciation for life) early on to move an athlete away from PTSD and depression risk and later incorporate methods of improving the growth least likely to occur to support the athletes in every possible outlet.

\section{Competition level and injury type.} There was no difference between a college and varsity athlete's ability to experience PTG. While it may seem as though a difference would be meaningful for this study, in reality, the finding of no difference between these groups provides evidence that competition level does not dictate PTG. Arming student-athletes with this knowledge could increase feelings of self-empowerment, because they have autonomy to perceive growth from an injury trauma despite their playing level. The same is true with injury type. Whether an athlete experienced a seasonor career-ending injury did not significantly impact their ability to experience PTG.

Understanding which variables do and do not impact PTG provides the information providers need to help athletes develop and function post-injury. Not to mention, greater awareness of why PTG occurs and how to better foster growth outcomes may help promote resilience against future traumas that will occur in the life of an athlete. As athletes incur injuries they, are more at risk for re-injury, which makes the presence of PTG even more meaningful.

\section{Study Limitations}

This study has several limitations. First, the findings rely on self-reports. Participants indicated whether or not they believe they experienced psychological growth following their injury. Self-reported data might not reflect real transformation (Sleijpen, Haagen, Mooren, \& Kleber, 2016). Second, the measurement tool collects retrospective data from participants. In other words, the measurement tool measured perceptions of change rather than actual pre- to post-trauma changes (Jayawickreme \& Blackie, 2014). Third, the cross-sectional nature of this study reduces the possibility of determining causality. Fourth, the research study examined type of sport and type of injury the athlete sustained. However, if an athlete identified as a multisport athlete the researchers were unable to label which sport the injury took place within, which removed the possibility of differentiating PTG score by sport injury. Fifth, the researchers did not explore the athletes current or past relationship with athletic identity. While the literature provides information on how athletic identity can impact an athletic injury the addition of the athlete's 
personal athletic identity could have added a new dimension or highlighted the research previously explored.

\section{Future Research}

As research on PTG continues to develop in other aspects of human experiences, those involved in the advancement of athletes should utilize such knowledge as a source for intervention development. The collaborative efforts of sport social workers, sport psychologists, athletic trainers, faculty athletic representatives and a coaching staff can aid in such intervening stances. Future research should explore the roles each of these individuals can play in best practices for promoting PTG. An understanding of which sport and when the injury occurred for the athlete in their career would be an important addition to a study to know when to intervene with which athletes. Future research should also explore what athletic variables promote or decrease PTG.

\section{Recommendations and Implications}

The results of this study provide evidence that athletes have the ability to perceive growth. Athletic trainers, sport psychologists, and coaches may find the use of the PTGI throughout an athlete's season can be helpful in monitorting an athlete's perception of growth. Recording such information on all athletes could provide a way to start the conversation about the impact an injury may have on an athlete. In particular, the possible negative behavioral outcomes of injury would be important to address to reduce adverse coping mechanisms.

Support is important during and after an injury (DeFreese \& Smith, 2011) and the use of the PTGI may show an athlete they have informational and social support. By acknowledging or becoming aware of informational and social support they may begin to have reductions in stress related to feelings of isolation and lack of knowledge. The researchers also recommend exploring the athletes five domains of growth. Greater responsiveness of an athletes' low and high areas of growth can become a catalyst for intervention and improved growth in those areas.

\section{Conclusion}

Greater awareness of one's trauma may influence the likelihood of increased PTG (Day, 2013). As PTG increases, the amount of stress felt due to trauma does not necessarily decrease; however, the awareness of negative emotional consequences due to trauma helps reduce remuneration (Day, 2013). Research of this nature helps to bring awareness to trauma and the role PTG can have in an athlete's life. After all, if professionals working in athletics along with individual athletes focus on growth past injury, there is likelihood of maintaining their self-identity.

\section{References}

Cabrita, T. M., Rosado, A. B., Leite, T. P., Serpa, S. O., \& Sousa, P. M. (2014). The relationship between athletic 
identity and career decisions in athletes. Journal of Applied Sport Psychology, 26, 471-481.

Centers for Disease Control and Prevention. (2015). CDC childhood injury report: unintentional injuries. Retrieved from https://www.cdc.gov/ safechild/child_injury_data.html.

Clement, D., Arvinen-Barrow, M., \& Fetty, T. (2015). Psychosocial responses during different phases of sport injury rehabilitation: A qualitative study. Journal of Athletic Training, 50, 95-104. Cosh, S., Crabb, S., \& LeCouteur, A. (2013). Elite athletes and retirement: Identity, choice, and agency. Australian Journal of Psychology, 65, 89-97.

Dabhauer, S. C., Russell, G. B., Tedeschi, R. G., Jesse, M. T., Vishnevsky, T., Daley, K., Carroll, S.,... \& Powell, B. L. (2013). A longitudinal investigation of postraumatic growth in adult patients undergoing treatment for acute leukemia. Journal of Clinical Psychological Medical Settings, 20, 13-24.

Day, M. C. (2013). The role of initial physical activity experiences in promoting posttraumatic growth in Paralympic athletes with an acquired disability. Disability and Rebabilitation an International, Multidisciplinary Journal, 35, 2064-2072.

DeFreese, J. D., \& Smith, A. L. (2013). Teammate social support, burnout, and self-determined motivation in collegiate athletes. Psychology of Sport and Exercise, 14, 258-265.

Duan, W., Gao, P., \& Gan, P. (2015). Relationships among trait resilience, virtues, post-traumatic stress disorder, and post-traumatic growth. PLOS One, 10, 1-13.

Engelhard, I. M., Lommen, M. J. J., \& Sijbrandij, M. (2015). Changing for better or worse? Posttraumatic growth reported by soldiers deployed to Iraq. Clinical Psychological Science, 3 , 789-796.

Faul, F., Erdfelder, E., Buchner, A., \& Lang, A. (2007). Statistical power analyses using $\mathrm{g}^{*}$ power 3.1: Test for correlation and regression analyses. Behavior Research Methods, 41, 11491160.

Ferguson, R. W., Green, A., \& Hansen, L. M. (2013). Game changers: Stats, stories and what communities are doing to protect young athletes. Washington, DC: Safe Kids Worldwide.

Field, A. (2009). Discovering statistics using SPSS. London, England: SAGE.

Heinrich, K. M., Spencer, V., Fehl, N., \& Poston, W. S. (2012). Mission fitness: Comparison of functional circuit training to traditional army physical training for active duty military. Military Medicine, 177, 1125-2012.

Heird, E. B., \& Steinfedt, J. A. (2013). An interpersonal psychotherapy approach to counseling student athletes: Clinical implications of athletic identity. Journal of College Counseling, 16, 143 157.

Ivarsson, A., Tranaeus, U., Johnson, U., \& Stenling, A. (2017). Negative psychological responses of injury and rehabilitation adherence effect on return to play in competitive athletes: A 
systematic review and meta-analysis.

Journal of Sports Medicine, 8, 27-32. Jayawickreme, E., \& Blackie, L. E. (2014).

Post-traumatic growth as positive personality change: Evidence, controversies, and future directions. European Journal of Personality, 28(4), 312-331.

Kampman, H., Hefferon, K., Wilson, M., \& Beale, J. (2015). "I can do things now that people thought were impossible, actually, things that I thought were impossible": A meta-synthesis of the qualitative findings on post traumatic growth and severe physical injury. Canadian Psychology Association, 56, 283-294.

Kay, M. C., Register-Mihalik, J. K., Gray, A. D., Djoko, A., Dompier, T. P., \& Kerr, Z. Y. (2017). The epidemiology of severe injuries sustained by $\mathrm{Na}$ tional Collegiate Athletic Association student-athletes, 2009-2010 through 2014-2015. Journal of Athletic Training, 52, 117-128

Kerr, Z. Y., Hayden, R., Dompier, T. P., \& Cohen, R. (2015). Association of equipment worn and concussion injury rates in National Collegiate Athletic Association football practices: 20042005 to 2008-2009 academic years. American Journal of Sports Medicine, 43, 1134-1141.

Koren, D., Norman, D., Ayala, C., Berman, J., \& Klein, E. M. (2005). Increased PTSD risk with combat-related injury: A matched comparison study of injured and uninjured soldiers experiencing the same combat events. American Journal of Psychiatry, 162, 276-282.

Kutcher, J. S., \& Ecker, J. T. (2010). Atrisk populations in sport-related concussion. Head and Neurologic Conditions, 9, 16-20.

Leung, Y. W., Alter, D. A., Prior, P. L., Stewart, D. E., Irvine, J., \& Grace, S. L. (2012). Posttraumatic growth in coronary artery disease outpatient relationship to degree of trauma and health service use. Journal of Psychosomatic Research, 72, 293-299.

Malhotra, M., \& Chebiyan, S. (2016). Posttraumatic growth: Positive changes following adversity- an overview. International Journal of Psychology and Behavioral Sciences, 6, 109-118.

Martin, L. A., Fogarty, G. J., \& Albion, M. J. (2014). Changes in athletic identity and life satisfaction of elite athletes as a function of retirement status. Journal of Applied Sport Psychology, 26, 96-110.

Morrill, E. F., Brewer, N. T., O’Neil, S. C., Lilie, S. E., Dees, C., Carey, L. A., \& Rimer, B. K. (2008). The interaction of post-traumatic growth and post-traumatic stress symptoms in predicting depressive symptoms and quality of life. PsychoOncology, 17, 948953.

Newcomer, R., \& Perna, F. (2003). Features of posttraumatic distress among adolescent athletes. Journal of Atbletic Training, 38,163-166.

Nishi, D., Matsuoka, Y., Yonemoto, N., Noguchi, H., \& Kim, Y. (2010). 
Peritraumatic distress inventory as a predictor of post-traumatic stress disorder after a severe motor vehicle accident. Psychiatry Clinical Neuroscience, 2010, 149-156.

Nishi, D., Kawahima, Y., Noguchi, H., Usuki, M., Yamashita, A., Koido, Y., \& Matsuooka, Y. J. (2016). Resilience, post-traumatic growth, and work engagement among health care professionals after the Great East Japan earthquake: A 4-year prospective follow-up study. Journal of Occupational Health, 58, 347-353.

Nolen-Hoeksema, S., \& Davis, C.G. (2004). Theoretical and methodological issues in the assessment and interpretation of posttraumatic growth. Psychological Inquiry, 15, 60-64.

Prentice, W. E. (2014) Principles of athletic training: A competency based approach. New York: McGraw-Hill Education.

Ramos, C., \& Leal, I. (2013). Posttraumatic growth in the after math of trauma: A literature review about related factors and application contexts. Journal of Psychology, Community. \& Health, 2, 43- 54.

Salim, J., Wadey, R., Diss, C. (2016). Examining hardiness, coping and stress-related growth following sport injury. Journal of Applied Sport Psychology, 28, 154-169.

Sears, S. R., \& Stanton, A. L. (2003). The yellow brick road and the emerald city: Benefit finding, positive reappraisal coping and posttraumatic growth in women with early-stage breast cancer. Health Psychology, 22, 487-497.

Sheinbein, S. (2016). Psychological effects of injury on the athlete: A recommendation for psychological intervention. American Medical Atbletic Association, 29, 8-10.

Sheu, Y., Chen, L., \& Hedegaard, H. (2016). Sports- and recreation-related injury episodes in the United States, 2011-2014. National Health Statistics Reports, 99, 1-10.

Sleijpen, M., Haagen, J., Mooren, T., \& Kleber, R. J. (2016). Growing from experience: An exploratory study of posttraumatic growth in adolescent refugees. European Journal of Psychotraumatology, 7, 1-10

Stambulova, N., Stephan, Y., \& Japhag, U. (2007). Athletic retirement: A cross-national comparison of elite French and Swedish athletes. Psychology of Sport and Exercise, 8, 101-118. Tamminen, K. A., Holt, N. L., \& Neely, K. C. (2013). Exploring adversity and the Potential for growth among elite female athletes. Psychology of Sport and Exercise, 14, 28-36.

Tedeschi, R. G., \& Calhoun, L. G. (1996). The posttraumatic growth inventory: Measuring the positive legacy of trauma. Journal of Traumatic Stress, 9, 455-471.

Timpka, T., Jacbsson, J., Dahlström, Ö., Kowalski, J., Bargoria, V., Ekberg, J., Nilsson, S., \& Renström, P. (2015). The psychological factor 'self-blame' predicts overuse injury among 
top-level Swedish track and field athletes: A 12-month cohort study. British Journal of Sports Medicine, 49, 1472-1477.

Williams, J. M., \& Krane, V. (2015) Applied Sport Psychology: Persona growth to peak performance ( $7^{\text {th }}$ ed.). New York: McGraw-Hill Education.
Zoellner, T., \& Maerker, A. (2006). Posttraumatic growth in clinical psychology: A critical review and introduction of a two-component model. Clinical Psychology Review, 26, 626-653. 